\title{
EVALUATE THE EFFECTIVENESS OF MOTIVATIONAL PACKAGE ON ENHANCING SELF- ESTEEM AND MAINTAIN ABSTINENCE, IN ALCOHOL DEPENDENT ADULTS IN A SELECTED DE-ADDITION CENTRE: A PILOT STUDY
}

\author{
Mr. Praveen L Subravgoudar* I Dr. J Rukumani**
}

*Research Scholar, Himalayan University, Itanagar, Arunachal Pradesh, India.

**Research Supervisor, Himalayan University, Itanagar, Arunachal Pradesh, India.

DOI: http://doi.org/10.47211/trr.2021.v07i01.008

\begin{abstract}
Alcohol dependence is a major health problem in every society, and in both developed and developing countries. It is usually referred to as the third most serious public health problem. Alcohol is a dangerous drug, which has been domesticated by traditions that predate history. It is intimate with our social life. Alcohol is a major public health problem today. In last three decades, many surveys have been carried out in India to assess the prevalence and co-morbidity of alcohol and drug uses. Important finding of these studies is that alcohol was the commonest substance used, i.e., 60-98\%. The research design used for the study was quasi-experimental research design. Total of 60 alcohol dependent adults, who met inclusion sampling criteria, were selected and randomly allocated 30 to experimental group and 30 to control group with the help of computer-generated random sequence numbers. Level of self-esteem and maintaining abstinence from alcohol among the alcohol depend ent adults was assessed by using Rosenberg Self-Esteem Scale and URICA Scale respectively. The participants of experimental group administered motivational package in 6 sessions, each day one session. Outcome variables were measured at three points in time; before intervention, $7^{\text {th }}$ day after intervention, and one month after intervention. Effects of the intervention were analyzed by repeated-measures ANOVA. Results shows the that Motivational Package was effective in enhancing Self-Esteem and maintaining abstinence, in alcohol dependent adults in a selected de-addition centre. A significant positive correlation $(r=0.0888)$ was found between post intervention level of self-esteem and maintaining abstinence from alcohol among adults in the experimental group and a significant negative correlation between $(r=-0.487)$ was found between post intervention level of self-esteem and maintaining abstinence from alcohol among adults in the control group. The study condudes that Motivational Package was effective in enhancing Self-Esteem and maintaining abstinence, in alcohol dependent adults in a selected de-addition centre.
\end{abstract}

Keywords: Motivational Package, Self-Esteem, Abstinence, Alcohol dependent adults, De-addition centre.

\section{ABOUT AUTHORS:}

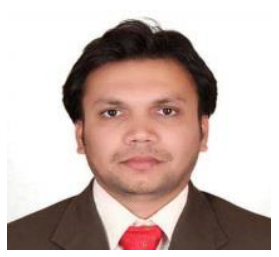

Author, Mr. Praveen L Subravgoudar is a Ph.D. Scholar at Himalayan University, Itanagar, Arunachal Pradesh, India.

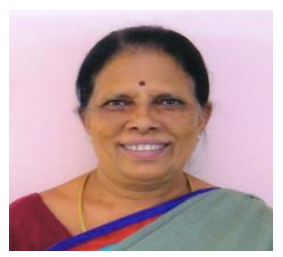

Author, Dr.J Rukumani is Research Supervisor in Himalayan University, Itanagar, Arunachal Pradesh, India. She has effective administrative and leadership skills. 


\section{INTRODUCTION}

Alcohol has been discovered and used by practically every culture in the world. This practice has invariably produced problems of alcohol misuse. Edwards and Gross introduced the concept of alcohol dependence syndrome as a cluster of core psycho physiological symptoms principally centered around a drive to consume alcohol ${ }^{1}$.

Global scenario: In 2010 it was estimated that about 1895 million people were alcohol dependent in the world. A large number of alcohol dependents found in USA, UK, Ireland, and India. Approximately two thirds of all adult Americanstake an alcohol drink in course of a year. ${ }^{2}$

Indian Scenario: In India about 10\% adult male and $0.08 \%$ adult females were found to be alcohol dependents. The incident rate was found to be 15.1\% in Mumbai, 14.3\% in Bangalore, 12.2\% in Delhi and 9\% in Chennai. The wide spread of abused drugs and alcohol has become a human tragedy. ${ }^{2}$

The alcohol dependence syndrome is considered as process, distinct from other alcohol related problemssuch as social, legal, work or health problems and this was accepted by all inter national classificatory systems ${ }^{3}$.

Alcohol dependence is a serious problem which affects not only an alcohol dependent individual but also others. The consumption of alcohol is a common feature both during fun, attempts at driving out pain and displeasure, the illusion of promoting one's self esteem; peer group interactions are the important factors which lead a person towards alcohol. ${ }^{4}$

Self-esteem refers to an individual's overall subjective feelings of personal value and self-worth. It can have an effect on many areas of life, including substance use and recovery.

People who have developed low self-esteem over time due to various reasons, commonly experience symptoms of anxiety or depression, and as a result, they turn to drugs and alcohol to mask their pain and insecurities. Low self-esteem results in self-medicating. In other words, those with low self-esteem turn to drugs and alcohol to numb pain and escape from reality. These substances are seen as a way to escape.

Motivation may be regarded as something which prompts, compels and energises an individual to act or behave in a particular manner at a particular time for attaining some specific goal or purpose ${ }^{5}$.

Motivation plays an important role in the treatment of alcohol dependent individuals. It is a 'self chosen' disease, which may lead to the assumption that unless the alcohol dependent deliberately chooses treatment and evidences a high level of motivation to change, the alcohol dependent will not profit from therapy. So, the level of motivation is an important factor to be found out before treatment among alcohol dependent individuals to make a better outcome. ${ }^{5}$

Screening for motivation is important if treatment is to be focused in those with a chance for success and also by this assessment of motivation one can plan out treatment programme to enhance a person's motivation to change. ${ }^{5}$

In 2018, 26.45 percent of people ages 18 or older reported (NSDUH, 2019) that they engaged in binge drinking in the past month; 6.6 percent reported that they engaged in heavy alcohol use in the past month. ${ }^{6}$

As per the report, in Karnataka about one-third of the adult male population uses alcohol; one out of two people who drink develop significant problems related to drinking. It has also been found that an alcohol dependent has a recurrent and relapsing illness which affects one in four drinkers in Karnataka. There were approximately five lakh alcohol dependent individuals in Karnataka. ${ }^{7}$

Alcohol has various effects on the consumer, his dependents and also on society. It may cause physical, psychological, social, marital, legal and medical problems. Recently the number of deaths due to alcohol dependence has increased. 40\% of deaths between 1992 and 1994 were attributed to alcohol consumption in Moscow. ${ }^{7}$

Motivation is the process by which man is impelled to seek some goal. An alcohol dependent may not be motivated by himself for treatment as alcohol dependents are found to have low level of aspiration and growth motivation. ${ }^{8}$

Nurses being one of the members of' health team, are in constant contact with patients who may have an early problem with alcohol but who are admitted for other reasons. They play a valuable role in the process of change by bolstering self- efficacy and offering positive re-enforcement for preparatory id eas and plan. ${ }^{9}$

Readiness to change can be identified by being sensitive to individual's willingness to disclose information, attentiveness to advice and suggest ions and. tendencies to askquestions. ${ }^{10}$ Since motivation is a significant component in response to therapy in alcohol dependent individuals, it is imperative that the motivational status in these patients is estimated, which may prove as a prognostic factor as well as indicate modes of psychotherapeutic interventions that will facilitate positive change. ${ }^{10}$

During the clinical postings of psychiatric nursing, the investigator came across several alcohol dependant patients. While working with them, the investigator felt that there is a need for "enhancing self motivation to 
maintain abstinence from alcohol".

By enhancing self motivation of alcohol dependent patients, a permanent abstinence from alcohol can be achieved. With this belief the investigator is interested to do this "Motivation Package to enhance self-esteem and maintain abstinence from alcohol" as a scientific research.

\section{OBJECTIVES OF THE STUDY.}

1. To assess the pre-intervention level of self - esteem and maintaining abstinence from alcohol among the alcohol dependent adults, both experimental and control group.

2. To provide nursing intervention in the form of motivational package to enhancing self - esteem and maintain abstinence from alcohol in the alcohol dependent adults of experimental group.

3. To assess the post interventional level of self - esteem and maintaining abstinence from alcohol among the alcohol dependent adults both experimental and control group.

4. To evaluate effectiveness of motivational package on enhancing self - esteem and maintain abstinence, in alcohol dependent adults, both experimental and control group.

5. To find significant correlation between self - esteem scores and maintaining abstine nce from alcohol scores among the alcohol dependent adults both experimental and control group.

6. To find significant association between level of self - esteem scores with selected socio-demographic variables among the alcohol dependent adults both experimental and control group.

7. To find significant association between level of maintaining abstinence from alcohol scores with selected socio demographic variables among the alcohol dependent adults both experimental and control group.

\section{HYPOTHESIS}

All the hypotheses are tested at 0.05 level of significance.

$\mathbf{H}_{1}$ : There will be significant difference in the post and pre interventional level of motivation in enhancing self esteem among the alcohol dependent adults both experimental and control group.

$\mathbf{H}_{2}$ : There will be significant difference in the post and pre interventional level of motivation in maintaining abstinence from alcohol among the alcohol dependent adults both experimental and control group.

$\mathbf{H}_{3}$ : There will be a significant correlation between self - esteem scores with maintaining abstine nce from alcohol scores among the alcoholdependent adults of experimental group.

$\mathbf{H}_{\mathbf{4}}$ : There will be a significant correlation between self - esteem scores with maintaining abstine nce from alcohol scores among the alcohol dependent adults of control group.

$\mathbf{H}_{5}$ : There will be a significant association between pre interventional level of self - esteem scores with selected socio-demographic variables among the alcohol dependent adults of experimental group.

$\mathbf{H}_{6}$ : There will be a significant association between pre interventional level of self - esteem scores with selected socio-demographic variables among the alcohol dependent adults of control group.

$\mathbf{H}_{7}$ : There will be significant association between pre interventional level of maintaining abstinence from alcohol scores with the selected socio-demographic variables among the alcohol dependent adults of experimental group.

$\mathbf{H}_{\mathbf{8}}$ : There will be significant association between pre interventional level of maintaining abstinence from alcohol scores with the selected socio-demographic variables among the alcohol dependent adults of control group.

\section{METHODS:}

Quasi-experimental research design was used. Sixty alcohol dependent adults, who met inclusion sampling criteria, were selected and randomly allocated 30 to experimental group and 30 to control group with the help of computer-generated random sequence numbers. Level of self - esteem and maintaining abstinence from alcohol among the alcohol dependent adults assesses by using Rosenberg Self-Esteem Scale and URICA Scale respectively. Both the tools are reliable as both the tools are standard tools. The participants of experimental group administered motivational package in 6 sessions. Outcome variables were measured at three points in time; before intervention, $7^{\text {th }}$ day after intervention, and one month after intervention. Effects of the intervention were analyzed by repeated-measures ANOVA. 


\section{ARTICLES}

RESULTS:

Section I: Demographic characteristics

Table 1: Frequency and percentage distribution of demographic variables of alcohol dependent adults in experimental and control group.

$N=60(30+30)$

\begin{tabular}{|c|c|c|c|c|}
\hline \multirow{2}{*}{ Demographic Variables } & \multicolumn{2}{|c|}{ Experimental Group } & \multicolumn{2}{|c|}{ Control Group } \\
\hline & No. & $\%$ & No. & $\%$ \\
\hline \multicolumn{5}{|l|}{ Age (in years) } \\
\hline $16-25$ years & 2 & 6.7 & - & - \\
\hline $26-35$ years & 15 & 50 & 14 & 46.7 \\
\hline $36-45$ years & 10 & 33.3 & 16 & 53.3 \\
\hline 46 and above & 3 & 10 & & \\
\hline \multicolumn{5}{|l|}{ Gender } \\
\hline Male & 29 & 96.7 & 28 & 93.3 \\
\hline Female & 1 & 3.3 & 2 & 6.7 \\
\hline \multicolumn{5}{|l|}{ Religion } \\
\hline Hindu & 15 & 50 & 18 & 60.0 \\
\hline Muslim & 9 & 30 & 6 & 20.0 \\
\hline Christian & 6 & 20 & 6 & 20.0 \\
\hline Others (Specify) & - & - & - & - \\
\hline \multicolumn{5}{|l|}{ Type of family } \\
\hline Nuclear family & 10 & 33.3 & 12 & 40.0 \\
\hline Joint family & 19 & 63.3 & 18 & 60.0 \\
\hline Extended family & 1 & 3.3 & - & - \\
\hline \multicolumn{5}{|l|}{ Marital status } \\
\hline Single & 4 & 13.3 & 4 & 13.3 \\
\hline Married & 21 & 70 & 18 & 60.0 \\
\hline Divorced & 5 & 16.7 & 4 & 13.3 \\
\hline Separated & - & - & 4 & 13.3 \\
\hline \multicolumn{5}{|l|}{ Education } \\
\hline Illiterate & 1 & 3.3 & 12 & 40.0 \\
\hline Primary & 3 & 10 & - & - \\
\hline Secondary & 16 & 53.3 & 12 & 40.0 \\
\hline Graduate / Professional & 10 & 33.3 & 6 & 20.0 \\
\hline \multicolumn{5}{|l|}{ Occupation } \\
\hline Unemployed & 3 & 10 & 4 & 13.3 \\
\hline Daily wages & 7 & 23.3 & 2 & 6.7 \\
\hline Business & 6 & 20 & 8 & 26.7 \\
\hline Private service & 12 & 40 & 16 & 53.3 \\
\hline Agriculture & 2 & 6.7 & - & - \\
\hline Others (Specify) & - & - & - & - \\
\hline \multicolumn{5}{|l|}{ Income (Rs. Per month) } \\
\hline Below 5000 & 2 & 6.7 & 2 & 6.7 \\
\hline $5001-10000$ & 7 & 23.3 & 8 & 26.7 \\
\hline $10001-20000$ & 15 & 50 & - & - \\
\hline $20001-30000$ & 6 & 20 & 20 & 66.7 \\
\hline 30001 and above & - & - & - & - \\
\hline \multicolumn{5}{|l|}{ Place of residence } \\
\hline Urban & 18 & 60 & 16 & 53.3 \\
\hline Rural & 9 & 30 & 12 & 40.0 \\
\hline Semi urban & 3 & 10 & 2 & 6.7 \\
\hline $\begin{array}{l}\text { History of alcoholism in } \\
\text { family }\end{array}$ & & & & \\
\hline
\end{tabular}




\section{ARTICLES}

\begin{tabular}{|c|c|c|c|c|}
\hline \multirow{2}{*}{ Demographic Variables } & \multicolumn{2}{|c|}{ Experimental Group } & \multicolumn{2}{|c|}{ Control Group } \\
\hline & No. & $\%$ & No. & $\%$ \\
\hline Yes & 17 & 56.7 & 20 & 66.7 \\
\hline No & 13 & 43.3 & 10 & 33.3 \\
\hline \multicolumn{5}{|c|}{$\begin{array}{l}\text { Duration of drinking alcohol (in } \\
\text { years) }\end{array}$} \\
\hline $1-5$ & 14 & 46.7 & 18 & 60.0 \\
\hline $6-10$ & 13 & 43.3 & 10 & 33.3 \\
\hline $11-15$ & 3 & 10 & 2 & 6.7 \\
\hline 16 and above & - & - & - & - \\
\hline \multicolumn{5}{|c|}{$\begin{array}{l}\text { Number of times treated for } \\
\text { alcohol dependence }\end{array}$} \\
\hline Once & 21 & 70 & 20 & 66.7 \\
\hline Twice & 7 & 23.3 & 10 & 33.3 \\
\hline Three times and above & 2 & 6.7 & - & - \\
\hline \multicolumn{5}{|l|}{ Duration of treatment } \\
\hline Less than 1 month & 15 & 50 & 14 & 46.7 \\
\hline One month & 11 & 36.7 & 14 & 46.7 \\
\hline Two months & 3 & 10 & 2 & 6.7 \\
\hline Three months and above & 1 & 3.3 & - & - \\
\hline \multicolumn{5}{|l|}{ Referredby } \\
\hline Self & 14 & 46.7 & - & - \\
\hline Health care personnel & 3 & 10 & 24 & 80.0 \\
\hline Friends & 11 & 36.7 & 4 & 13.3 \\
\hline Others (Specify) & 2 & 6.7 & 2 & 6.7 \\
\hline \multicolumn{5}{|l|}{ Any time tried to quit alcohol } \\
\hline Yes & 12 & 40 & 10 & 33.3 \\
\hline No & 18 & 60 & 20 & 66.7 \\
\hline
\end{tabular}

$p<0.001,{ }^{*} p<0.01, S-$ Significant, N.S - Not Significant

Section II: To assess the pre-intervention level of self - esteem and maintaining abstinence from alcohol among the alcohol dependent adults, both experimental and control group.

Table 2: Frequency and percentage distribution of pre-intervention level of self-esteem among alcohol dependent adults in experimental and control group.

$N=60(30+30)$

\begin{tabular}{|l|c|c|c|c|}
\hline \multirow{2}{*}{ Self-Esteem } & \multicolumn{2}{c|}{ Experimental Group } & \multicolumn{2}{c|}{ Control Group } \\
\cline { 2 - 5 } & No. & $\%$ & No. & $\%$ \\
\hline Poor Self-Esteem (10-20) & 20 & 66.7 & 11 & 36.7 \\
\hline Moderate Self-Esteem (21-30) & 8 & 26.7 & 13 & 43.3 \\
\hline High Self-Esteem (31-40) & 2 & 6.7 & 6 & 20.0 \\
\hline
\end{tabular}




\section{ARTICLES}

Table 3: Frequency and percentage distribution of pre-intervention level of maintaining abstinence from alcohol among the alcohol dependent adults in experimental and control group.

$N=60(30+30)$

\begin{tabular}{|l|c|c|c|c|}
\hline \multicolumn{1}{|c|}{$\begin{array}{c}\text { Maintaining Abstinence from } \\
\text { Alcohol }\end{array}$} & \multicolumn{2}{c|}{ Experimental Group } & \multicolumn{2}{c|}{ Control Group } \\
\cline { 2 - 5 } & No. & $\%$ & No. & $\%$ \\
\hline Low $(\leq 8)$ & 12 & 40.0 & 2 & 6.7 \\
\hline Moderate $(8-11)$ & 8 & 26.7 & 15 & 50.0 \\
\hline High $(>11)$ & 10 & 33.3 & 13 & 43.3 \\
\hline
\end{tabular}

Section III: To assess the post interventional level of self - esteem and maintaining abstinence from alcohol among the alcohol dependent adults both control and experimental group.

Table 4: Frequency and percentage distribution of post intervention 1 level of self-esteem among alcohol dependent adults in experimental and control group.

\begin{tabular}{|l|c|c|c|c|}
\hline \multirow{2}{*}{\multicolumn{1}{|c|}{ Self-Esteem }} & \multicolumn{2}{c|}{ Experimental Group } & \multicolumn{2}{c|}{ Control Group } \\
\cline { 2 - 5 } & No. & $\%$ & No. & $\%$ \\
\hline Poor Self-Esteem (10-20) & - & - & 9 & 30 \\
\hline Moderate Self-Esteem(21-30) & 15 & 50 & 15 & 50 \\
\hline High Self-Esteem (31-40) & 15 & 50 & 6 & 20 \\
\hline
\end{tabular}

$p<0.001, S-$ Significant

Table 5: Frequency and percentage distribution of post intervention 2 level of self-esteem among alcohol dependent adults in experimental and control group.

\begin{tabular}{|l|c|c|c|c|}
\hline \multicolumn{1}{|c|}{ Self-Esteem } & Experimental Group & \multicolumn{2}{c|}{ Control Group } \\
\cline { 2 - 5 } & No. & $\%$ & No. & $\%$ \\
\hline Poor Self-Esteem $(10-20)$ & 8 & 26.7 & 6 & 20 \\
\hline Moderate Self-Esteem (21-30) & 2 & 6.7 & 18 & 60 \\
\hline High Self-Esteem (31-40) & 20 & 66.7 & 6 & 20 \\
\hline
\end{tabular}

$\mathrm{p}<0.001, \mathrm{~S}-$ Significant

\section{Self-Esteem $\quad$ Poor Self- \\ Esteem}

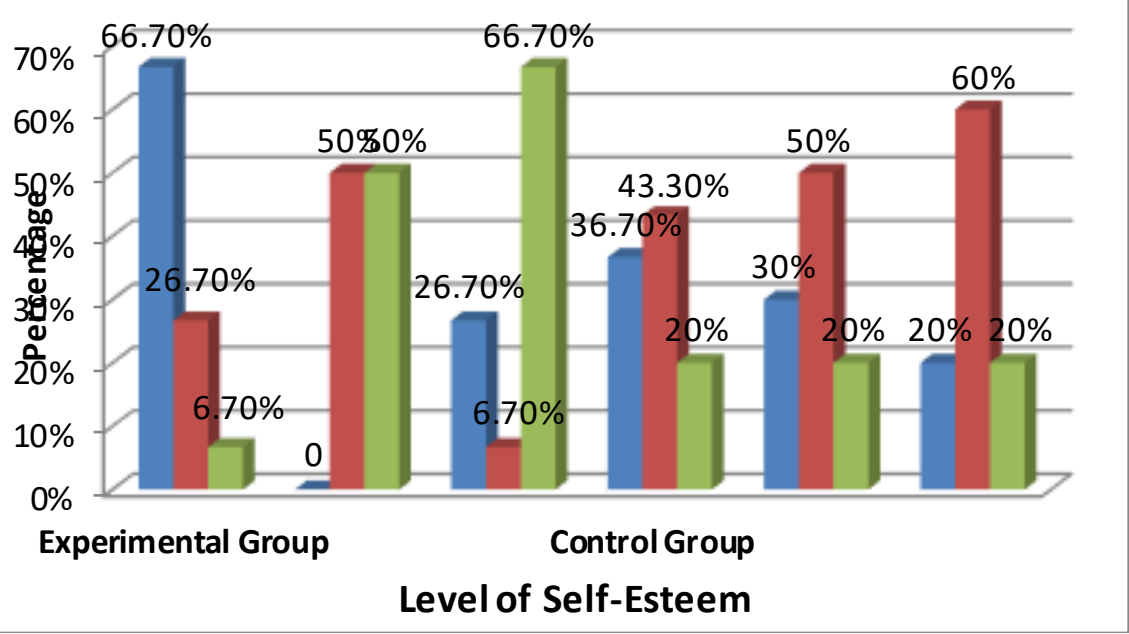

Figure .1 Percentage distribution of pre-intervention, post intervention 1 and post intervention 2 level of selfesteem among alcohol dependent adults in experimental and control group. 


\section{ARTICLES}

Table 6: Frequency and percentage distribution of post intervention 1 level of maintaining abstinence from alcohol among the alcohol dependent adults in experimental and control group.

\begin{tabular}{|c|c|c|c|c|}
\hline \multirow{3}{*}{ Maintaining Abstinence from Alcohol } & & & $=60(30$ & \\
\hline & \multicolumn{2}{|c|}{ Experimental Group } & \multicolumn{2}{|c|}{ Control Group } \\
\hline & No. & $\%$ & No. & $\%$ \\
\hline $\operatorname{Low}(\leq 8)$ & - & - & 7 & 23.3 \\
\hline Moderate $(8-11)$ & 11 & 36.7 & 21 & 70 \\
\hline High (>11) & 19 & 63.3 & 2 & 6.7 \\
\hline
\end{tabular}

$* * * \mathrm{p}<0.001, \mathrm{~S}-$ Significant

Table 7: Frequency and percentage distribution of post intervention 2 level of maintaining abstinence from alcohol among the alcohol dependent adults in experimental and control group.

\begin{tabular}{|l|c|c|c|c|}
\hline \multirow{2}{*}{ Maintaining Abstinence from Alcohol } & Experimental Group & \multicolumn{2}{c|}{ Control Group } \\
\cline { 2 - 5 } & No. & $\%$ & No. & $\%$ \\
\hline Low $(\leq 8)$ & 4 & 13.3 & 2 & 6.7 \\
\hline Moderate $(8-11)$ & 6 & 20 & 25 & 83.3 \\
\hline High $(>11)$ & 20 & 66.7 & 3 & 10 \\
\hline
\end{tabular}

$* * * \mathrm{p}<0.001, \mathrm{~S}-$ Significant

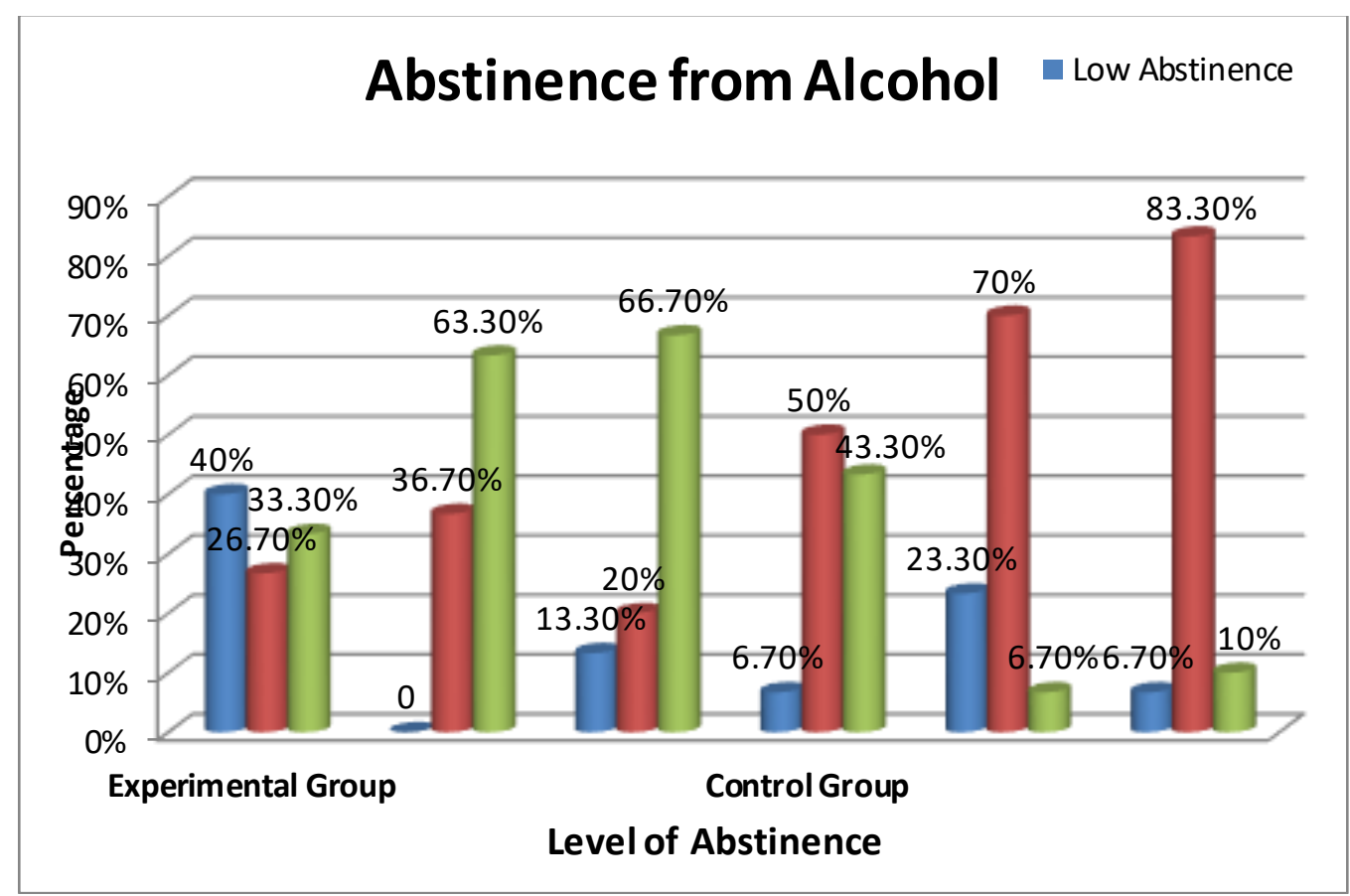

Figure .2 Percentage distribution of pre-intervention, post intervention 1 and post intervention 2 level of maintaining abstinence from alcohol among the alcohol dependent adults in experimental and control group.

Section IV: To evaluate effectiveness of motivational package on enhancing self - esteem and maintain abstinence, in alcohol dependent adults, both experimental and control group.

Table 8: Comparison of post intervention level of self-esteem among adults between the experimental and control group. $\mathrm{N}=60(30+30)$

\begin{tabular}{|c|c|c|c|c|c|c|}
\hline \multirow{2}{*}{ Self-Esteem } & \multicolumn{2}{|c|}{ Experimental Group } & \multicolumn{2}{|c|}{ Control Group } & \multirow{2}{*}{$\begin{array}{c}\text { Mean Diff. } \\
\text { Score }\end{array}$} & \multirow{2}{*}{ Unpaired ' $\mathrm{t}$ ' test } \\
\hline & Mean & S. D & Mean & S. D & & \\
\hline Post Intervention 2 & 26.2 & 3.78 & 15.7 & 3.78 & 10.5 & $\begin{array}{c}t=10.74 \\
P=0.0001, S\end{array}$ \\
\hline
\end{tabular}

$* * * p<0.05, S-$ Significant, N.S - Not Significant 
Table 8 displays calculated student independent ' $\mathrm{t}$ ' test value of $\mathrm{t}=10.74$ in the post intervention shows that there was significant difference in the level of self-esteem from alcohol in which the alcohol dependent adults in the experimental group had experienced significant improvement in their level of self-esteem after the administration of motivational package than the adults in the controlgroup.

The motivational package helped the alcohol dependent adults to enhancing self - esteem and maintaining abstinence from alcohol among the alcohol dependent adults both experimental groups. The effectiveness was sustained till the second post intervention assessment also. Hence the research hypotheses, " $\mathrm{H}_{1}$ : There is significant improvement in the level of self - esteem among the alcohol dependent adults in the experimental group than the control group as measured by Rosenberg Self-Esteem scale" was accepted.

Table 9: Comparison of post intervention level of abstinence, among adults between the experimental and control group.

\begin{tabular}{|c|c|c|c|c|c|c|}
\hline \multirow{3}{*}{$\begin{array}{l}\text { Maintaining abstinence } \\
\text { from alcohol }\end{array}$} & & & & & & $N=60(30+30)$ \\
\hline & \multicolumn{2}{|c|}{$\begin{array}{c}\text { Experimental } \\
\text { Group }\end{array}$} & \multicolumn{2}{|c|}{ Control Group } & \multirow{2}{*}{$\begin{array}{l}\text { Mean Diff. } \\
\text { Score }\end{array}$} & \multirow{2}{*}{ Unpaired ' $t$ ' test } \\
\hline & Mean & S. D & Mean & S. D & & \\
\hline Post Intervention 2 & 115.1 & 20.06 & 78.3 & 20.06 & 36.8 & $\begin{array}{c}t=7.10 \\
P=6.16173 \\
S\end{array}$ \\
\hline
\end{tabular}

$* * * p<0.05, \mathrm{~S}-$ Significant, N.S - Not Significant

Table 9 displays calculated student independent ' $t$ ' test value of $t=7.10$ in the post intervention shows that there was significant difference in the level of maintaining abstinence from alcohol in which the alcohol dependent adults in the experimental group had experienced significant improvement in their level of maintaining abstinence after the administration of motivational package than the adults in the control group. Hence the research hypotheses, " $\mathrm{H}_{2}$ : There is significant improvement in the level of maintaining abstinence from alcohol among the alcohol dependent adults in the experimental group than the control g roup as measured by URICA scale" was accepted.

Section V: To find significant correlation between self - esteem scores with maintaining abstinence from alcohol scores among the alcohol dependent adults both experimental and control group.

Karl Pearson's Correlation Coefficient was calculated to examine the relationship between self - esteem scores with maintaining abstinence from alcohol scores among the alcohol dependent adults both experimental and control group.

Table 10.: Correlation between of pre intervention and post intervention level of self-esteem and maintaining abstinence from alcohol among adults in the experimental group.

\begin{tabular}{|c|c|c|c|c|c|}
\hline \multirow{3}{*}{ Variables } & & & & & $\mathbf{N}=60$ \\
\hline & \multicolumn{2}{|c|}{ Self Esteem } & \multicolumn{2}{|c|}{ Abstinence } & \multirow{2}{*}{$\begin{array}{c}\text { Karl Pearson's } \\
\text { Correlation Value }\end{array}$} \\
\hline & Mean & S. D & Mean & S. D & \\
\hline Post Intervention & 27.44 & 3.43 & 7.86 & 1.69 & $\begin{array}{c}r=\mathbf{0 . 0 8 8 8} \\
P=0.64076, N S\end{array}$ \\
\hline
\end{tabular}

$\mathrm{p}<0.05$, Significant, N.S - Not Significant

Table 10. shows technically a positive correlation between the variables was weak, observed between selfesteem and maintaining abstinence at post intervention 2 level among alcohol dependent adults in the experimental group.

This infers that when the self esteem among alcohol dependent adults increases then their maintaining abstinence level from alcohol also increases.

Regarding the, " $\mathrm{H}_{3}$ : There is a significant correlation between level of self - esteem scores with maintaining abstinence from alcohol scores among the alcohol dependent adults in experimental group."

Karl Pearson's correlation coefficient showed a significant correlation at pre-test and a significant positive correlation at second post intervention between self-esteem scores with maintaining abstinence from alcohol scores among the alcohol dependent adults of experimental group. Hence the $\mathbf{H}_{3}$ research hypothesesacce pted. 
Table 11: Correlation between of pre intervention and post intervention level of self-esteem and maintaining abstinence from alcohol among adults in the control group.

$N=60$

\begin{tabular}{|c|c|c|c|c|c|}
\hline \multirow{2}{*}{ Variables } & \multicolumn{2}{|c|}{ Self Esteem } & \multicolumn{2}{|c|}{ Abstinence } & \multirow{2}{*}{$\begin{array}{c}\text { Karl Pearson's } \\
\text { Correlation Value }\end{array}$} \\
\hline & Mean & S. D & Mean & S. D & \\
\hline Post Intervention & 17.88 & 2.15 & 3.68 & 0.46 & $\begin{array}{c}r=-0.487 \\
P=0.00634, S\end{array}$ \\
\hline
\end{tabular}

$p<0.05$ N.S - Not Significant

Table 11 indicates technically a negative correlation between the variablesis only weak, between self - esteem scores with maintaining abstinence from alcohol scores among the alcoholdependent adults of control group. Regarding the, " $\mathrm{H}_{4}$ : There is a significant correlation between level of self - esteem scores with maintaining abstinence from alcohol scores among the alcohol dependent adults in control group."

Karl Pearson's correlation coefficient showed a significant correlation at second post intervention between self - esteem scores with maintaining abstine nce from alcohol scores among the alcohol dependent adults of control group. Hence the $\mathbf{H}_{4}$ research hypotheses accepted.

Section VI: Association of pretest self esteem score of alcohol dependent adults with selected demographic variables in both experimental and control group.

The Chi-Square test was calculated to find out the association between pretest self esteem score of alcohol dependent adults with selected demographic variables in both experimental and control group.

The demographic variable education had shown statistically significant association with pretest self esteem score $\left(\chi^{2}=17.772\right.$, table value $\left.=12.592\right)$ at $p<0.05$ level in experimental group.

With regard to the " $\mathrm{H}_{5}$ : The re is a significant association between pre interventional level of self - esteem scores with selected socio-demographic variables among the alcohol dependent adults in experimental group", there was a significant association found between pre interventional level of motivation in enhancing self - esteem scores with selected socio-de mographic variables among the alcohol dependent adults of control group, such as education. Hence the $\mathbf{H}_{5}$ is accepted.

The demographic variable number of times treated for alcohol dependence had shown statistically significant association with pretest self esteem score $\left(\chi^{2}=8.790\right.$, table value $\left.=5.991\right)$ at $p<0.05$ level in control group.

With regard to the " $\mathbf{H}_{6}$ : There is a significant association between pre interventional level of self - esteem scores with selected socio-demographic variables among the alcohol dependent adults in control group", there is a significant association found between and pre interventional level of motivation in enhancing self - esteem scores with selected socio-demographic variables among the alcohol de pendent adults of experimental group, such as number of times treated for alcohol dependence. Hence the $\mathbf{H}_{\mathbf{6}}$ is accepted.

Section VII: To find significant association between level of maintaining abstinence from alcohol scores with selected socio demographic variables among the alcohol dependent adults both experimental and control group.

The Chi-Square test was calculated to find out the association between pre interventional level of maintaining abstinence score of alcohol dependent adults with selected demographic variables in both experimental and control group.

The demographic variable age, income, place of residence, history of alcoholism in the family, duration of treatment, referred by and any time tried to quit alcohol had shown statistically significant association with pre interventional level of maintaining abstinence score $\left(\chi^{2}=19.267\right.$, table value $\left.=12.592\right),\left(\chi^{2}=15.765\right.$, table value $=12.592),\left(\chi^{2}=17.000\right.$, table value $\left.=9.488\right),\left(\chi^{2}=11.063\right.$, table value $\left.=12.592\right),\left(\chi^{2}=15.682\right.$, table value $=$ $12.592),\left(\chi^{2}=13.856\right.$, table value $\left.=12.592\right)$ and $\left(\chi^{2}=6.806\right.$, table value $\left.=5.991\right)$ respectively at $p<0.05$ level in experimental group.

With respect to " $\mathrm{H}_{7}$ : There is significant association between pre interventional level of maintaining abstinence from alcohol scores with the selected socio-demographic variables among the alcohol dependent adults in experimental group", there was a significant association found between pre interventional level of maintaining abstinence from alcohol scores with selected socio-demographic variables among the alcohol dependent adults both experimental group, such as age, income, place of residence, history of alcoholism in the family, duration of treatment, referred by and any time tried to quit alcohol. Hence the $\mathbf{H}_{7}$ is accepted.

The demographic variables had shown there was no statistically significant association with pre interventional level of maintaining abstinence from alcohol. 
With respect to " $\mathrm{H}_{8}$ : There is significant association between pre interventional level of maintain ing abstinence from alcohol scores with the selected socio-demographic variables among the alcohol dependent adults in control group", there was no significant association found between pre interventional level of maintaining abstinence from alcohol scores with selected socio-demographic variables among the alcohol dependent adults of control group. Hence the $\mathrm{H}_{\mathbf{8}}$ is rejected.

\section{DISCUSSION}

In order to find meaningful answersto research questions, the collected data must be processed, analyzed in an orderly and coherent fashion, so that patternsand relationships can be discussed.

\section{Section I: Demographic characteristics.}

In this study majority of the samples i.e., 15 (50\%) from experimental groupand 14 (46.7\%) from control group were belonging to $26-35$ years followed by 10 (33.3\%) from experimental group and 16 (53.3\%) from control group were belonging to $36-45$ years, 3 (10\%) from experimental group and no one from control group were belonging to 46 and above and 2 (6.7\%) from expe rimental group and no one from control group were belonging to $16-25$ years.

The present study findings are supported by Mohan, (2008) study on Alcohol abuse in a rural community in India. About $50 \%$ of both male and female users we re between 20 and 39 years of age. Physical, economic and social problems were reported by a significantly higher percentage of alcoholics than socialdrinkers. ${ }^{11}$

Section II: To evaluate effectiveness of motivational package on enhancing self - esteem and maintain abstinence, in alcohol dependent adults, both experimental and control group.

Calculated student independent ' $\mathrm{t}$ ' test value of $\mathrm{t}=10.74$ in the post intervention shows that there was significant difference in the level of self-esteem from alcohol in which the alcohol dependent adults in the experimental group had experienced significant improvement in their level of self-esteem after the administration of motivational package than the adults in the control group.

Calculated student independent ' $t$ ' test value of $t=7.10$ in the post intervention shows that there was significant difference in the level of maintaining abstinence from alcohol in which the alcohol dependent adults in the experimental group had experienced significant improvement in their level of maintaining abstinence after the administration of motivational package than the adults in the controlgroup.

The present study findings were supported by Ramya M et al. (2019) study to evaluate the effectiveness of Motivational Therapy on Enhancing Self-esteem, to maintain Abstinence among Alcohol Dependent Patients in Sri Sai Foundation psychiatric hospital, Tamaka, Kolar. The sample size of 80 alcohol dependent patients was selected by using non-probability, convenient sampling technique. The findings of the study revealed that after Motivational therapy mean scores of self-esteem level i.e., 18.75 with SD of 2.14 was higher than before Motivational therapy mean score i.e., 9.51 with SD of 1.58. The obtained t value 32.2 was greater than the table value (1.960) at 0.05 level of significance which indicates that Motivational the rapy was effective on enhancing self-esteem levels of alcohol dependent patients. ${ }^{12}$

Section III: To find significant correlation between self - esteem scores with maintaining abstinence from alcohol scores among the alcohol dependent adults both experimental and control group.

Findings of Karl Pearson's Correlation Coefficient was indicating technicallya negative correlation ( $r=-0.487$, P $=0.00634$ ) between the variables is only weak, between self - esteem scores with maintaining abstinence from alcohol scores among the alcohol de pendent adults of control group.

Findings shows technically a positive correlation $(r=0.0888, P=0.64076)$ between the variables was weak, observed between self-esteem and maintaining abstinence at post intervention 2 level among alcohol dependent adults in the experimental group.

This infers that when the self esteem among alcohol dependent adults increases then their maintaining abstinence level from alcohol also increases.

The present study findings were supported by Ms.K.Banupriya (2018) study to assess the effectiveness of structured teaching programme on awareness and readiness to change the abusive behavior among persons with alcohol use in the selected community at Coimbatore. The study concluded that the improvement means a score of awareness of hazards of alcoholism and its management was 11.16 with the standard deviation of 7.32 and the "t" value was 10.77 which was significant at 0.05 level. In case of readiness to change, the mean value was 32.42 with the standard deviation was 22.99 and the "t" value was 9.07 which was significant at 0.05 level. There was a significant positive correlation between awareness and readiness to change the abusive behavior found in the analysis. ${ }^{13}$ 
Section IV: To find significant association between level of self - esteem scores with selected sociodemographic variables among the alcohol dependent adults both experimental and control group.

The Chi-Square test was calculated to find out the association between pretest self esteem score of alcohol dependent adults with selected demographic variables in both experimental and control group.

The demographic variable education had shown statistically significant association with pretest self esteem score $\left(\chi^{2}=17.772\right.$, table value $\left.=12.592\right)$ at $p<0.05$ level in experimental group.

The demographic variable number of times treated for alcohol dependence had shown statistically significant association with pretest self esteem score $\left(\chi^{2}=8.790\right.$, table value $\left.=5.991\right)$ at $p<0.05$ level in control group.

The present study findings were contradictory to the study conducted by Ramya M et al. (2019) study to evaluate the effectiveness of Motivational Therapy on Enhancing Self-esteem, to maintain Abstinence among Alcohol Dependent Patients in Sri Sai Foundation psychiatric hospital, Tamaka, Kolar. The sample size of 80 alcohol dependent patients were selected by using non-probability, convenient sampling technique. The chi-square test and fisher's exact test computed between after Motivational therapy of self-esteem level and selected sociodemographic data showed that there was no significant association between the after Motivational therapy of self-esteem level and selected socio-demographic data. ${ }^{12}$

Section V: To find significant association between the level of maintaining abstinence from alcohol scores with selected socio demographic variables among the alcohol dependent adults both experimental and control group.

The Chi-Square test was calculated to find out the association between pre interventional level of maintaining abstinence score of alcohol dependent adults with selected demographic variables in both experimental and control group.

The demographic variable age, income, place of residence, history of alcoholism in the family, duration of treatment, referred by and any time tried to quit alcohol had shown statistically significant association with pre interventional level of maintaining abstinence score $\left(\chi^{2}=19.267\right.$, table value $\left.=12.592\right),\left(\chi^{2}=15.765\right.$, table value $=12.592),\left(\chi^{2}=17.000\right.$, table value $\left.=9.488\right),\left(\chi^{2}=11.063\right.$, table value $\left.=12.592\right),\left(\chi^{2}=15.682\right.$, table value $=$ $12.592),\left(\chi^{2}=13.856\right.$, table value $\left.=12.592\right)$ and $\left(\chi^{2}=6.806\right.$, table value $\left.=5.991\right)$ respectively at $p<0.05$ level in experimental group.

The demographic variables had shown there was no statistically significant association with pre interventional level of maintaining abstinence from alcohol in control group.

The present study findings were supported by Anupama Korlakunta, Swaroopa R S Chary, Pavan Kumar C M Reddy (2012) to assess the reasons for relapse in alcohol dependent patients among Mamata General Hospital, Khammam, at Andhra Pradesh, India. The study sample was collected from 190 in-patients with Alcohol Dependence Syndrome (ADS). The results revealed that, craving was noted as most common cause for relapse in alcohol dependent patients. The study concluded that, there was significant association betw een age at first drink, age at dependence, duration of dependence, other Co-morbid diagnosis of patients and relapse. ${ }^{14}$

The present study findings were contradictory to the study conducted by Mugbool Pasha (2005) to assess the level of motivation to remain abstinent from alcohol consumption in adult male clients and enhancing self motivation. In view of the nature of the problem URICA scale questionnaire was used to assess the level of motivation. Purposive sampling technique was used to select 30 alcohol dependent adult males for the main study. The result showed that the selected socio-demographic variables none of the variable had significance in relation to level of motivation of the participants. ${ }^{16}$

\section{CONCLUSIONS:}

The study concludes that Motivational Package was effective in enhancing Self-Esteem and maintaining abstinence, in alcohol dependent adults in a selected de-addition centre. 


\section{REFERENCES.}

1. Mallika S. An assessment of motivation among relapsed and abstinent alcohol dependent individuals. Unpublished MSc. Nsg. Dissertation, NIMHANS, Bangalore. 1997; 21-46.

2. Raghanathan S, Alcohol in the world. World Health Forum; September 2004: 1-5.

3. King MP, Tucker JA. Natural resolution of alcohol problems without treatment. Addictive behaviour; 1991:537-41.

4. Abraham J. A prospective study of treatment outcome in alcohol dependence from a de-addiction centre in India. India Journal of psychiatry1997.39 (1) : 18-23.

5. Mangal S K. Advanced Educational psychology. Delhi prentice Hall of India Pvt Ltd; 1993: 111.

6. Substance Abuse and Mental Health Services Administration(SAMHSA). 2018 National Survey on Drug Use and Health (NSDUH). Table 2.1B - Tobacco Product and Alcohol Use in Lifetime, Past Year, and Past Month among Persons Aged 12 or Older, by Age Group: Percentages, 2017 and 2018.

7. Vijay Kumar R. Alcoholism abuse a serious problem in state Editorial in the HINDU, Bangalore: dec-18th : 2001.

Available at:

https://www.samhsa.gov/data/sites/default/files/cbhsqreports/NSDUHDetailedTabs2018R2/NSDUHDetT absSect2pe2018.htm\#tab2-1b. Accessed 12/2/19

8. Bakshi, Jaidev. Aspiration levelamong alcoholics and alcoholics. Indian journal of clinical psychology; 1984; 2:1-4.

9. Kozier, Barbara and Erb Gleonara. Fundamentals of Nursing. Philadelphia: Mosby publishing company;1987:116-30

10. Who. Global strategy to reduce harmful use of alcohol. [Homepage on the Internet]. 2008 [cited 2012 Nov 27]. Available from: http://www.Who.int/ substance- abuse/activities/grshua/en

11. Mohan D. (2008). Alcohol abuse in India Part II: Characteristics of alcohol users, Drug alcohol Depend". 14(2): 121-128.

12. Ramya M et al. (2019). Motivational Therapy on Enhancing Self-esteem in Alcohol Patients. J Clin Biomed Sci. 9(3): 77-80.

13. Ms.K. Banupriya. A study to assess the effectiveness of structured teaching programme on awareness and readiness to change the abusive behavior among persons with alcohol use in selected community at Coimbatore. A Dissertation Submitted to The Tamil Nadu Dr. M. G. R. Medical University, Chennai - 32. In Partial Fulfillment of the Requirement for the Award of the Degree of Master of Science in Nursing Branch - V Mental Health Nursing, 2018.

14. Anupama Korlakunta, Swaroopa R S Chary, Pavan Kumar C M Reddy. Reasons for relapse in patients with alcohol dependence. 2012:13(2), 108-114.

15. Mugbool Pasha. A quasi-experimental study to assess the effectiveness of nursing intervention on enhancing self motivation to maintain abstinence, in alcohol dependent adults in a selected de-addition centre at Bangalore. Dissertation submitted to the Rajiv Gandhi University of Health Sciences, Karn ataka, Bangalore, 2005. 